\title{
Occupations as an Outcome Measure in a Clinical Trial: Fragile X Syndrome and Sertraline (Preliminary Results)
}

Michelle Beckwith, OTS | Brina Nguyen, CAPS, OTS | Jennifer Sik, OTS | Kenneth Yu, OTS | Laura Greiss Hess, PhD, OTR/L (Faculty Advisor) Dominican University of California | Department of Occupational Therapy

\section{Background}

Fragile $X$ Syndrome (FXS) is the most common form of inherited intellectual and developmental disability.

$\uparrow$ Offers a genetic model to understanding autism spectrum disorder

- Manifests with behavioral problems, anxiety, and sensory processing difficulties

A battery of standardized, normreferenced assessments and parent checklists are frequently used as outcome measures in clinical trials.

$\downarrow$ The addition of interview methods will provide family voice and personal stories thus affording: - An occupation-centered lens to empirically examine living with FXS and the impact on family life

- A measurement for contextually-based changes as an outcome measure for use in clinical trials

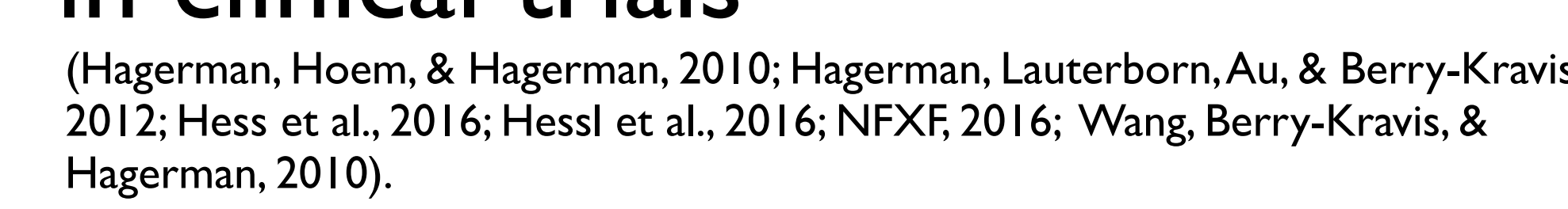

\section{Research Question} Can qualitative interview methods serve as occupational performance between treatment and placebo groups?

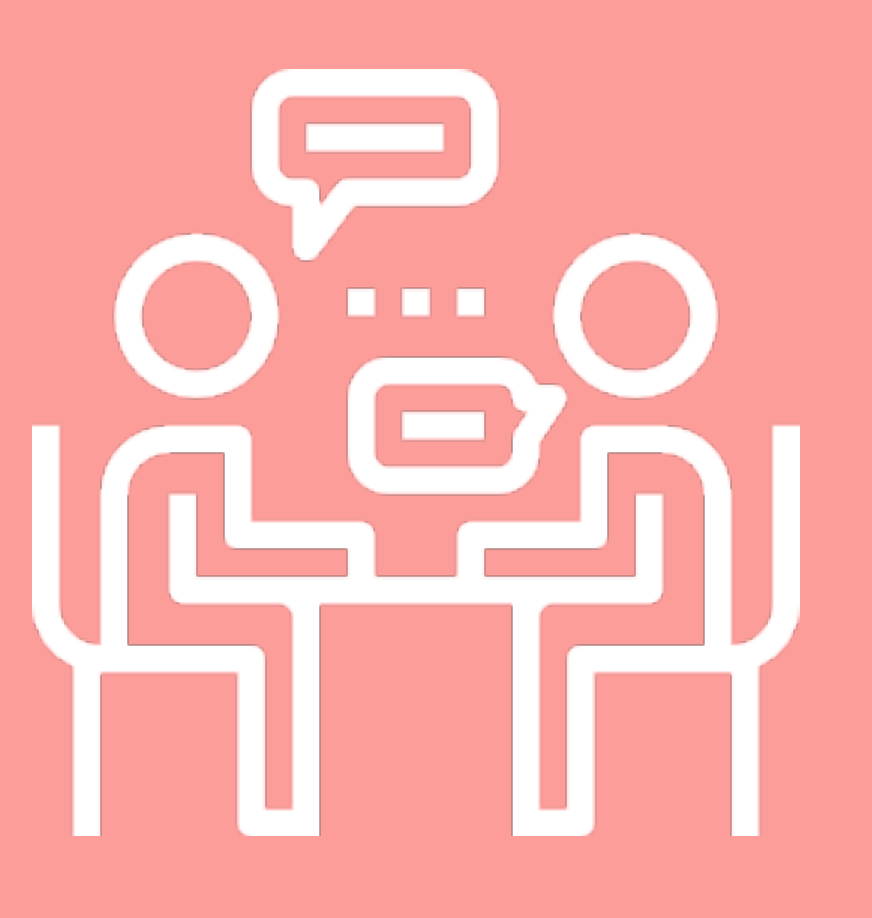

\section{Methods}

Design: Qualitative (interview methods)

Population: Families with children diagnosed with full mutation FXS enrolled in UC Davis MIND Institute sertraline (Zoloft $\circledast$ ) clinical trial

Interview sample for this study .12 interviews

-6 placebo

.6 treatment

UC Davis MIND Institute RCT 83
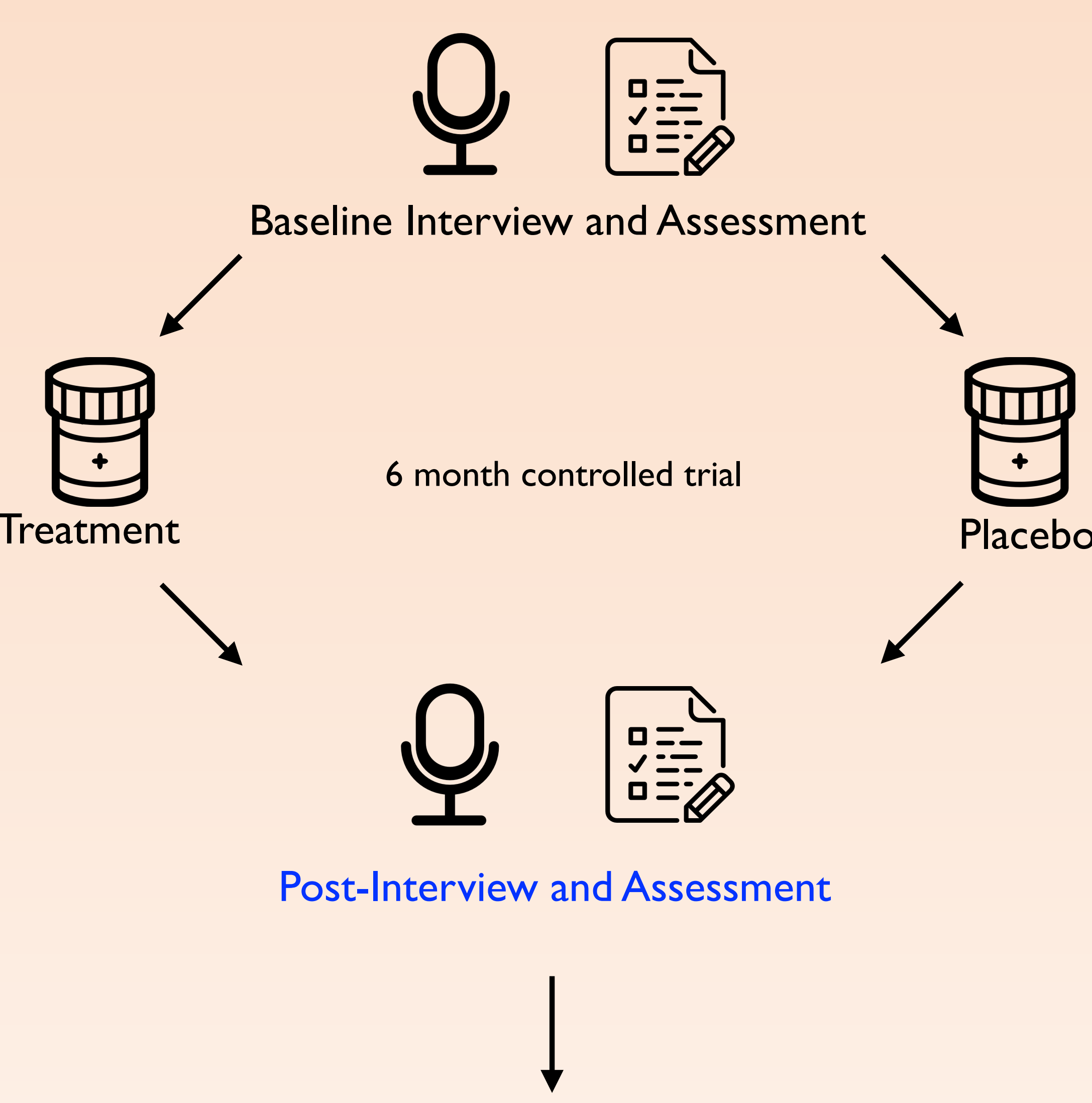

This Study

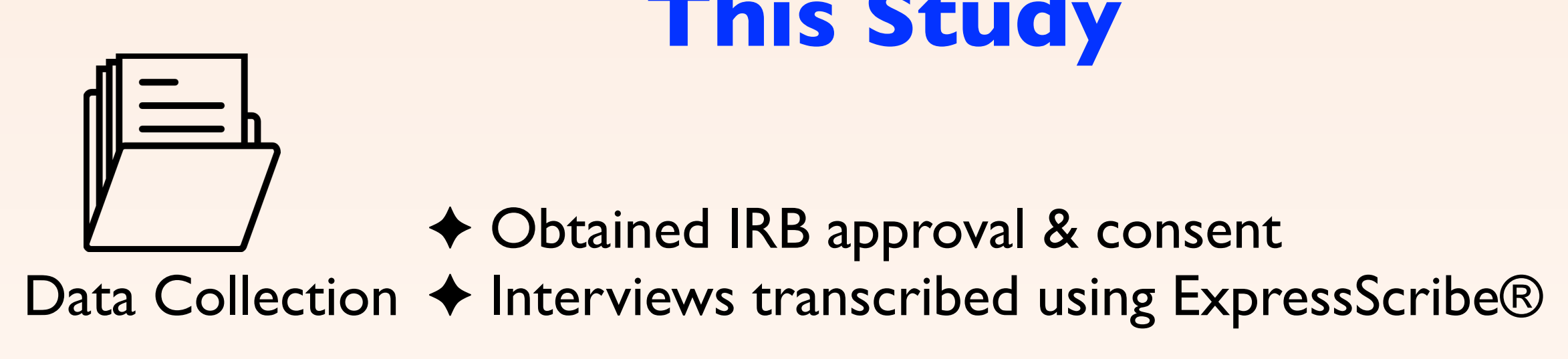

+ Constant comparison method (CCM) - Operationalization of codes \& themes - All coding blind to group assignment -Each researcher assigned 3 transcripts CCM \& re-operationalizali ization of codes \& themes + Independently reviewed all coded excerpts
+ Consensus coding of $100 \%$ codes

\section{Results}

Preliminary trends indicated improvements in the sertraline treatment group compared to the placebo group in the following areas:
$\downarrow$ Anxiety
Maladaptive behaviors
$\downarrow$ Expressive \& receptive communication
Sensory (Less)

The sertraline group did not show greater improvements than the placebo group in the following areas:
+ Community/social
$\downarrow$ Sensory (More)

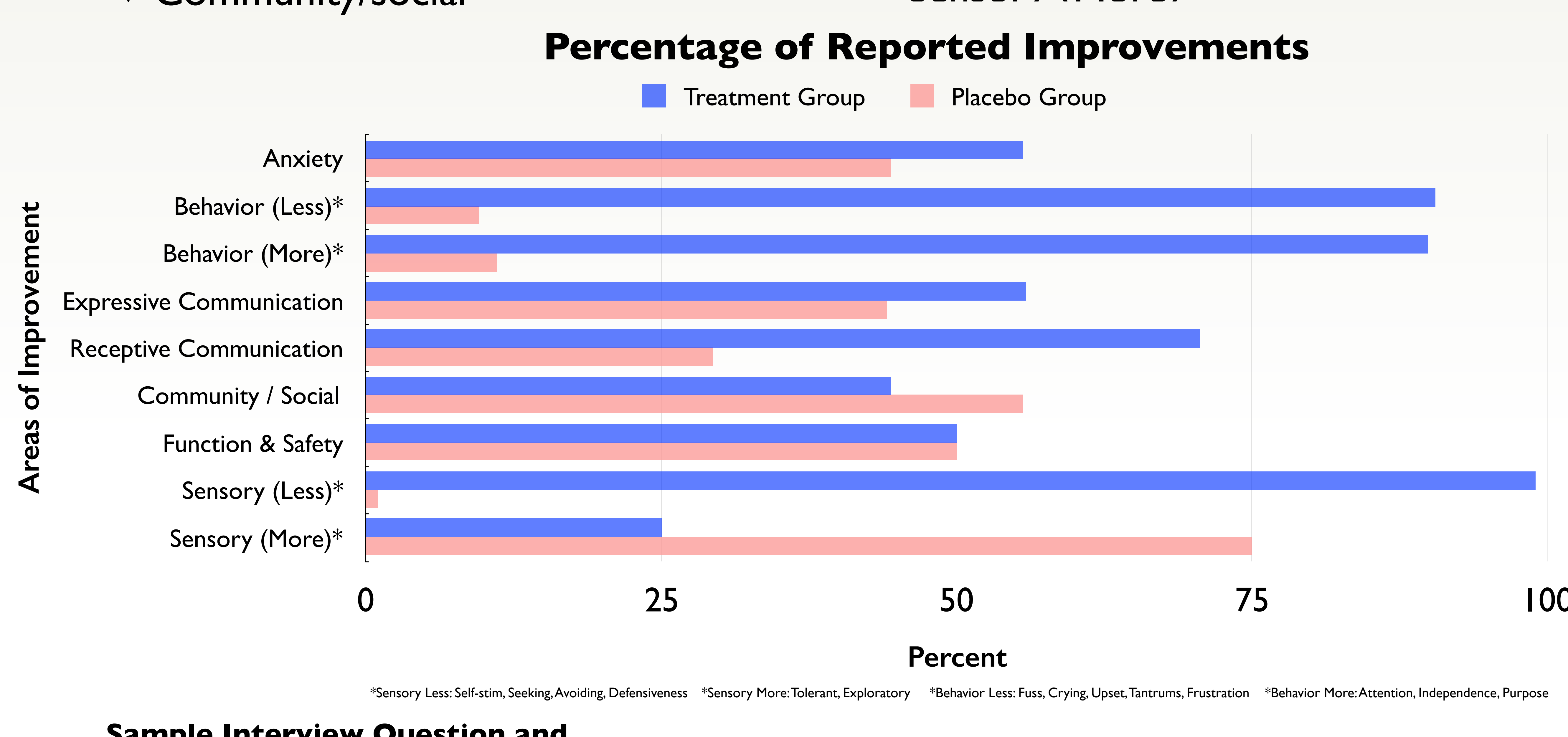

Sample Interview Question and

"Have you noticed any changes related to anxietyas that inpicted you as a finily?"

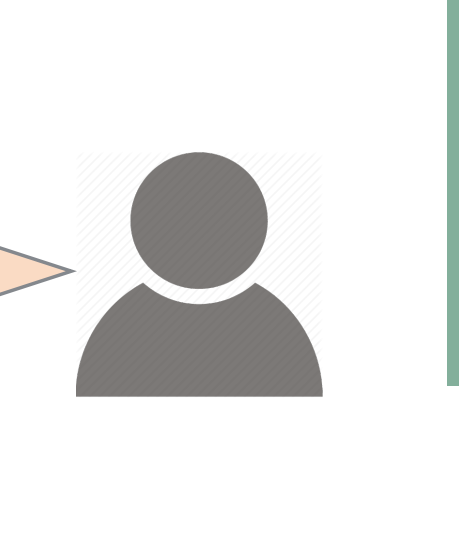

eal meds because he is sort of dealing with his anxiety better. I am finding that it's not such of a struggle. His episodes aren't as big. They are still there. He's the next thing."

Communication "He has improved tremendously. He is using more signs, he is very expressive, he uses his (acial express

Behavior
"He has calmed down. He's more interactive with play. Doing his own play things, playing himself"

Sensory Strategies/Community \& Social "I think the fact that we expose him to so afraid of being in a big noisy space with lights."

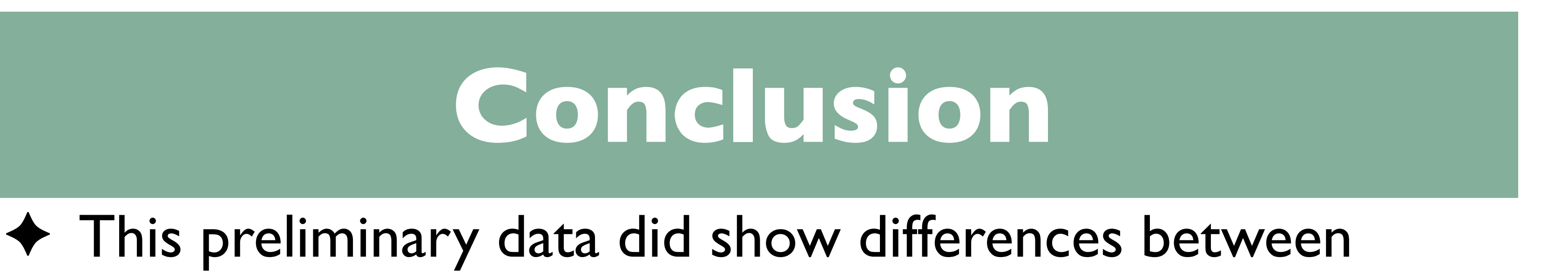

This preliminary data did show differences between groups in several areas

$\downarrow$ Occupational therapy intervention and clinical research should include parent perspectives, not just standardized assessments

$\downarrow$ Families within the FXS community felt a sense of altruism from participating in the study

$\downarrow$ Future directions to include a larger sample for analysis Acknowledgments

The researchers would like to sincerely thank the UC

Davis MIND Institute and families in the FXS community who contributed to this research. This study was funded by Health Resources and Services Administration (HRSA, \#R40MC2264I). 